\title{
Protective Effect of Curcumin on Liver Damage Induced by Biliary Obstruction in Rats
}

\author{
Cengiz Erenoğlu', Mehmet Kanter², Burhan Aksu³, Tamer Sağıroğlu', Süleyman Ayvazz, Cevat Aktaş4, Mustafa Erboğa² \\ ${ }^{1}$ Department of General Surgery, Faculty of Medicine, Trakya University, Edirne, Turkey \\ ${ }^{2}$ Department of Histology and Embryology, Faculty of Medicine, Trakya University, Edirne, Turkey \\ ${ }^{3}$ Department of Pediatric Surgery, Facult of Medicine, Trakya University, Edirne, Turkey \\ ${ }^{4}$ Department of Histology and Embryology, Faculty of Medicine, Namık Kemal University, Tekirdağ, Turkey
}

\begin{abstract}
Objective: The aim of this study is to evaluate the possible protective effects of curcumin against cholestatic oxidative stress and liver damage in common bile duct ligated rats.

Material and Methods: A total of 18 male Wistar albino rats were divided into three groups: control, common bile duct ligation (BDL) and BDL+curcumin. Each group contained 6 animals. The rats in the curcumin treated group were given curcumin $(100 \mathrm{mg} / \mathrm{kg})$ once a day orally for 14 days, starting 3 days prior to BDL operation. Following 14 days of treatment, all the animals were decapitated and liver tissue samples were obtained for histopathological investigation.
\end{abstract}

Results: The changes demonstrating the bile duct proliferation and fibrosis in expanded portal tracts, including the extension of proliferated bile ducts into lobules, mononuclear cells, and neutrophil infiltration into the widened portal areas, were observed in BDL group. Treatment of BDL with curcumin attenuated liver damage. Both the elevated alpha smooth muscle actin ( $\alpha$-SMA), and the activity of TUNEL in the BDL were observed to be reduced with the curcumin treatment.

Conclusion: Our data indicate that curcumin reduced BDL-induced cholestatic liver injury, bile duct proliferation, fibrosis.

Key Words: Curcumin, immunohistochemistry, TUNEL, liver, bile duct ligation

Received: 14.06 .2010

Accepted: 02.07.2010

\section{Introduction}

Obstructive cholestasis in the liver occurs in various diseases in children and adults, such as biliary atresia, gallstones, primary biliary cirrhosis, and periampullary tumors. Biliary obstruction causes hepatocellular injury and leads to progressive hepatic fibrogenesis (1). In fibrogenesis, the rate of hepatic collagen synthesis increases (2). Which is also found to be stimulated in hepatocytes exposed to free radicals (3).

Complete biliary obstruction causes cholestatic injury to the liver, including hepatocellular necrosis and apoptosis, bile duct epithelial cell proliferation, stellate cell activation, and, eventually, liver fibrosis (4). Even though the exact mechanisms of biliary fibrosis are unknown, one of the implicated factors is the toxic effect of hydrophobic bile salts on the hepatocytes and biliary epithelial cells by obstruction of the bile flow in the liver (5). Immunohistochemically, it was found that the majority of cells observed in the fibrosis regions were positive cells (spindle cells) for alpha smooth muscle actin $(\alpha-S M A)$. It is suggested that the spindle cells, probably transforming from Ito cells or myofibroblasts, play an important role in the pathogenesis of hepatic fibrosis (6).

Curcumin, a widely used orange-yellow curry pigment from turmeric (Curcuma longa), has been designated to be a forceful anti-inflammatory, anti-cancer and antioxidant agent, and is under preclinical trial for cancer prevention and antiinflammation $(7,8)$. Lately, curcumin was shown to inhibit the production of nitric oxide (NO) and the expression of inducible NO synthase (iNOS) (9). Overproduction of NO and oxidants seem to be important factors in the pathology of the inflammatory process in lung injury. Inhibition of iNOS and protection of oxidant effects have been effective in reducing tissue damage in several models of inflammation (9-11).

The aim of the present study is to assay the preventive and therapeutic potential of curcumin on rat hepatic damage induced by BDL and to elicit the role of the antioxidant effect.

\section{Materials and Methods}

The Ethical Committee of Trakya University approved all animal procedures and the experimental protocol. Efforts were made to minimize animal suffering and reduce the number of animals used in experimental groups.

\section{Animals}

In this study, 18 healthy male Wistar albino rats, weighing 200-250 $\mathrm{g}$ and averaging 16 weeks of age were utilized. Food and tap water were available ad libitum. In the windowless 
animal quarter, automatic temperature $\left(21 \pm 1^{\circ} \mathrm{C}\right)$ and lighting controls (12 h light/12 h dark cycle) were instituted. Humidity ranged from $55 \%$ to $60 \%$. All animals received human care according to the criteria outlined in the "Guide for the Care and Use of Laboratory Animals" prepared by the National Academy of Sciences and published by the National Institutes of Health.

\section{Experimental groups}

A total of 18 male Wistar albino rats were divided into three groups with 6 animals in each: control, BDL and BDL+ curcumin.

\section{Experimental protocols}

The rats were anesthetized with ketamine $(90 \mathrm{mg} / \mathrm{kg})$ and xylazine $(10 \mathrm{mg} / \mathrm{kg}$ ) intraperitoneally (i.p.) and the bile duct (BD) exposed through a midline abdominal incision. The BD was located and obstructive jaundice induced by a double ligation with $5 / 0$ silk and transsection of the BD in the supraduodental part between the lowermost tributary of the bile duct and the uppermost tributary of the pancreatic duct. The rats in the curcumin treated group were given curcumin (in a dose of $100 \mathrm{mg} / \mathrm{kg}$ body weight, Sigma, St Louis, MO, USA) once a day orally by intra gastric intubation for 14 days, starting 3 days prior to the BDL operation. Control and BDL untreated rats were also intubated with the same volume of saline as the BDL treated animals receiving curcumin. After 14 days of treatment, the animals were decapitated. Liver tissue samples were obtained for histopathological investigation.

\section{Histopathologic evaluation}

At the end of the surgical procedure, the liver specimens were individually immersed in Bouin's fixative, dehydrated in alcohol and embedded in paraffin. Lobular architecture, presence of inflammation, necrosis and ductular proliferation were investigated. Lobular and portal inflammation, focal hepatocyte necrosis and interface activity were scored as in the modified hepatitis activity index of Ishak et al. (12). Fibrosis was assessed in sections stained with Masson's trichrome. The histopathological fibrosis was evaluated as: no fibrosis (scored as 0), portal fibrosis (scored as 1), septal fibrosis (scored as 2), incomplete cirrhosis (scored as 3), and complete cirrhosis (scored as 4). Histopathological examination was carried out by a pathologist who had no prior knowledge of the animal groups.

\section{Immunohistochemistry}

The harvested liver tissues were fixed in Bouin's, embedded in paraffin and sectioned at $5 \mu \mathrm{m}$ thickness. Immunocytochemical reactions were performed according to the $A B C$ technique described by Hsu et al. (13) The procedure involved the following steps: (1) endogenous peroxidase activity was inhibited by $3 \% \mathrm{H}_{2} \mathrm{O}_{2}$ in distilled water for $30 \mathrm{~min}$; (2) the sections were washed in distilled water for $10 \mathrm{~min}$; (3) non-specific binding of antibodies was blocked by incubation with normal goat serum (DAKO X 0907, Carpinteria, CA) with PBS, diluted 1:4; (4), the sections were incubated with specific mouse monoclonal anti actin smooth muscle antibody (Cat. \# MS-113-P, Neomarkers, USA) and diluted 1:50 for $1 \mathrm{~h}$ at room temperature; (5). The sections were washed in PBS $3 \times 3 \mathrm{~min}$; (6) then were incubated with biotinylated anti-mouse IgG (DAKO LSAB 2 Kit); (7). The sections were then washed in PBS $3 \times 3 \mathrm{~min}$; (8) and incubated with $A B C$ complex (DAKO LSAB $2 \mathrm{Kit}$ ); (9), then the sections were washed in PBS $3 \times 3 \mathrm{~min} ;(10)$ and peroxidase was detected with an aminoethylcarbazole substrate kit (AEC kit; Zymed Laboratories); (11). The sections were washed in tap water for 10 min and then dehydrated; (12) the nuclei were stained with hematoxylin; and (13) the sections were mounted in DAKO paramount. All dilutions and thorough washes between steps were performed using phosphate buffered saline unless otherwise specified. All steps were carried out at room temperature unless otherwise specified. As a negative control, primary antibody was replaced with PBS.

The number of $\alpha$-SMA positive hepatic stellate cells (HSCs) in each specimen was scored using the system developed previously (14) with modifications. Ten randomly selected septa were scored for each specimen in every experiment as follows: $0=$ no positive response; $1=$ less than $10 \%$ of $\mathrm{HSCs} ; 2=11$ $20 \%$ of HSCs; $3=21-40 \%$ of HSCs; $4=$ more than $40 \%$ of HSCs.

\section{TUNEL assay}

The TUNEL method, which detects fragmentation of DNA in the nucleus during apoptotic cell death in situ, was employed using an apoptosis detection kit (TdT-Fragel ${ }^{\mathrm{TM}}$ DNA Fragmentation Detection Kit, Cat. No. QIA33, Calbiochem, USA). All reagents listed below are from the kit and were prepared following the manufacturer's instructions. Five- $\mu \mathrm{m}$-thick pulmonary sections were deparaffinized in xylene and rehydrated through a graded ethanol series as described previously. They were then incubated with $20 \mathrm{mg} / \mathrm{ml}$ proteinase $\mathrm{K}$ for 20 minutes and rinsed in TBS. Endogenous peroxidase activity was inhibited by incubation with $3 \%$ hydrogen peroxide. Sections were then incubated with equilibration buffer for 10 30 second and then TdT-enzyme in a humidified atmosphere at $37^{\circ} \mathrm{C}$, for 90 minutes. They were subsequently put into prewarmed working strength stop/wash buffer at room temperature for 10 minutes and incubated with blocking buffer for 30 minutes. Each step was separated by thorough washes in TBS. Labelling was revealed using $D A B$, counter staining was performed using Methyl green, and sections were dehydrated, cleared and mounted.

The number of TUNEL positive hepatic cells, including hepatocytes and nonparenchymal cells, in each specimen was also scored. Ten randomly selected septa were scored for each specimen in every experiment as follows: $0=$ no positive response; $1=$ less than $10 \%$ of hepatic cells; $2=11-20 \%$ of hepatic cells; $3=21-40 \%$ of hepatic cells; $4=$ more than $40 \%$ of hepatic cells.

\section{Statistical analysis}

All statistical analyses were carried out using SPSS statistical software (SPSS for windows, version 11.0). All data were presented in mean ( \pm ) standard deviations (S.D.). Differences in measured parameters among the three groups were analyzed with a nonparametric test (Kruskal-Wallis). Dual comparisons between groups exhibiting significant values were evaluated with a Mann-Whitney U-test. These differences were considered significant when the probability was less than 0.05 . 


\section{Results}

\section{Histopathologic findings}

The architecture of hepatic lobules of the normal control rats was complete, and there was neither fibroplasia nor inflammatory cell infiltration. Acute biliary obstruction was accompanied by distorsion of liver parenchyma around portal triads when compared with the control rats (Fig. 1a, b). Ductular proliferation and fibrosis were the predominant findings in portal areas of BDL-rats (Fig. 1b), However, in the rats of the BDL group, the lobules of the liver were separated and surrounded by collagen fibers, which resulted in apparent pseudo-lobules. Infiltration of inflammatory cells were also observed. Treatment of BDL rats with curcumin attenuated alterations in liver damage (Fig. 1c, Table 1).

\section{Immunohistochemical findings}

The staining for $\alpha$-SMA positive cells in the control livers was present only in vascular smooth muscle cells (Fig. 2a). Since $\alpha$-SMA was expressed in activated HSCs, immunostaining for this protein was used to detect the development of hepatic fibrosis. The positive stainings for $\alpha$-SMA were greatly increased, especially in vascular smooth muscle cells and sinusoids and also in the cells of portal ducts, fibrotic septa, perisinuses and around the proliferated bile ducts (Fig. 2b).
The $\alpha$-SMA positive cells in the BDL group were observed to be reduced with the curcumin treatment (Fig. 2c, Table 1).

\section{TUNEL findings}

The number of TUNEL-positive cells in the control group was negligible (Fig. 3a). When liver sections were TUNEL stained, there was a clear increase in the number of positive cells in the BDL treated rats in the liver parenchyma (Fig. 3b). Treatment of curcumin markedly reduced the reactivity and the number of TUNEL positive cells (Fig. 3c, Table 1).

\section{Discussion}

Bile duct obstruction causes a well-known cell proliferation and accumulation of matrix inside the liver, which eventually results in end stage liver disease and cirrhosis. Despite the ability to alleviate obstruction mechanicall, liver damage continues unabated with persistent inflammatory and fibrogenic responses $(15,16)$.

Immediate pathological alterations in biliary epithelial cells are initiated by the accumulation of biliary constituents secondary to bile duct obstruction (17). BDL is associated with the development of oxidant injury, hepatic fibrosis, biliary cirrhosis, portal hypertension, and a hyperdynamic circulation that is a dynamic process implying different rates of progres-
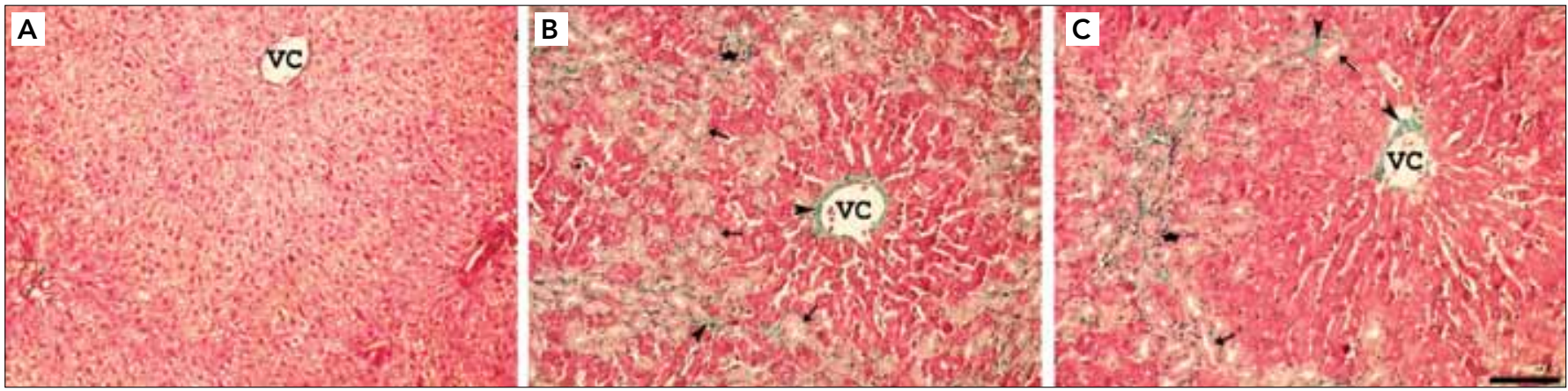

Figure 1. Light microscopy of liver tissue in different groups. Masson trichrome: (A) In controls, normal liver architecture was seen; (B) After BDL, ductular proliferation, necrosis, and fibrosis were the predominant; (C) BDL induced histopathologic changes in rat liver reduced by curcumin treatment (VC: vena centralis, Asterisk: inflammatory cells, Arrowhead: collagen fibers, Arrow: bile ducts)
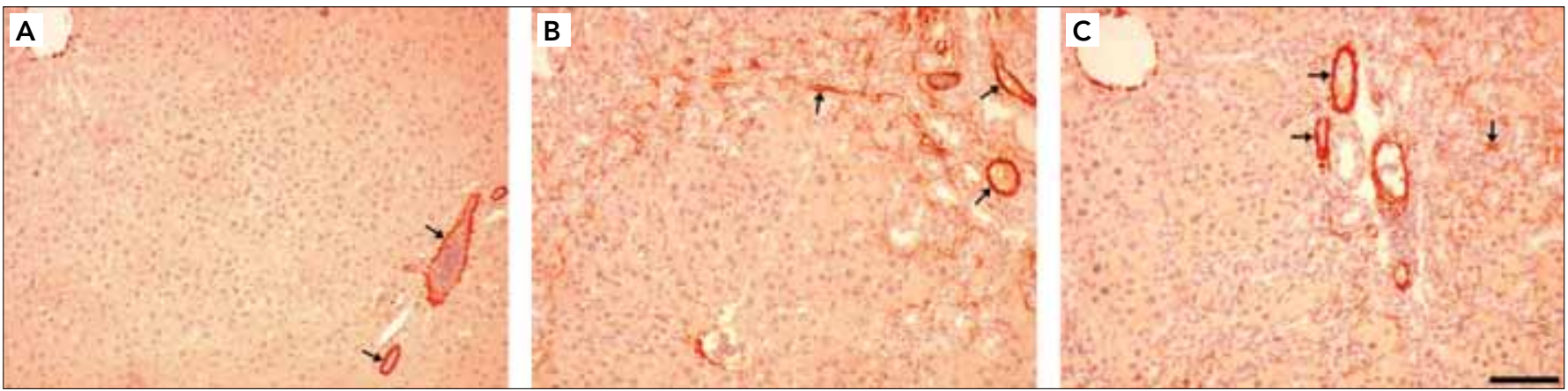

Figure 2. Light microscopy of liver tissue in different groups. $\alpha$-SMA: (A) In controls, the staining for $\alpha$-SMA positive cells was present only in vascular smooth muscle cells. (B) After BDL, the positive stainings for $\alpha$-SMA were greatly increased especially in vascular smooth muscle cells and sinusoids and also in the cells of portal ducts, fibrotic septa, perisinuses and around the proliferated bile ducts. (C) The $\alpha$-SMA positive cells reduced with the curcumin treatment (Arrow: $\alpha$-SMA positive cells) 


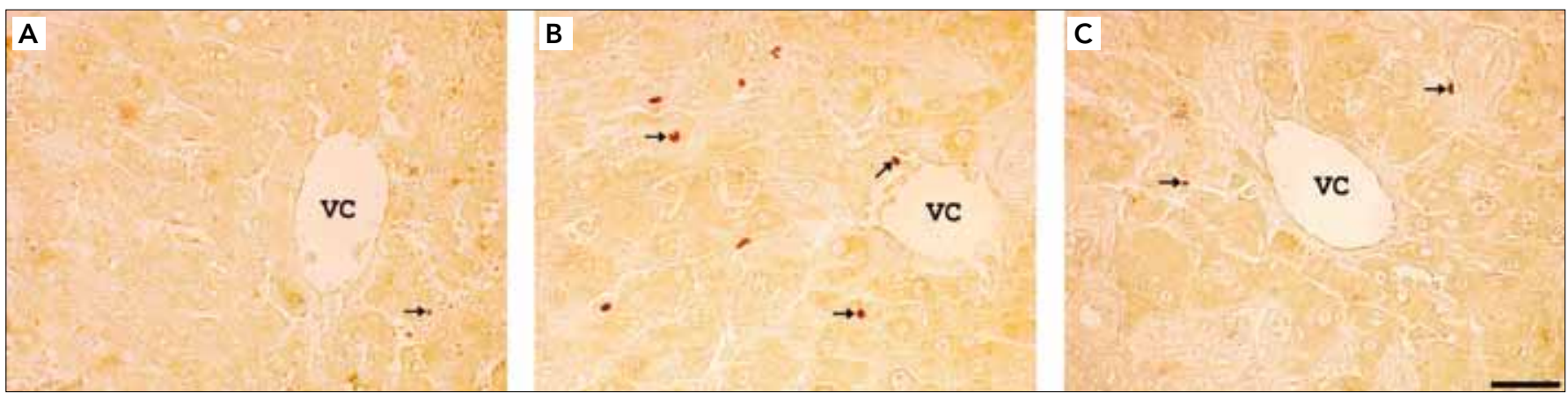

Figure 3. Light microscopy of liver tissue in different groups. TUNEL: (A) In control group, a few TUNEL-positive cells are observed in the liver parenchyma; (B) After BDL, there was a clear increase in the number of positive cells in the liver parenchyma; (C) Treatment of curcumin markedly reduced the reactivity and the number of TUNEL positive cells (VC: vena centralis, Arrow: TUNEL-positive hepatocytes), (Masson trichrome and TUNEL, scale bar, $50 \mu \mathrm{m}$ )

Table 1. Comparison of fibrosis and the expression of $\alpha$-SMA and TUNEL in control, BDL and BDL+curcumin groups

\begin{tabular}{|lccc|}
\hline & Control & BDL & BDL+curcumin \\
\hline Fibrosis & $0.00 \pm 0.00$ & $2.52 \pm 0.14^{\mathrm{a}}$ & $1.24 \pm 0.09^{\mathrm{b}}$ \\
$\alpha$-SMA & $0.08 \pm 0.01$ & $2.49 \pm 0.12^{\mathrm{a}}$ & $0.63 \pm 0.05^{\mathrm{c}}$ \\
TUNEL & $0.09 \pm 0.01$ & $2.59 \pm 0.16^{\mathrm{a}}$ & $0.66 \pm 0.06^{\mathrm{c}}$ \\
\hline
\end{tabular}

Kruskal-Wallis test was used for statistical analysis. Values are expressed as means $\pm S D, n=6$ for each group

${ }^{a} p<0.0001$ compared with control, ${ }^{b} p<0.001$ compared with control, ${ }^{c} p<0.01$ compared with control

sion or regression (18). It has been reported that $\mathrm{BDL}$ reduces antioxidant defences and increases free radical formation (19). Some studies have suggested the role of free radicals in the modulation of hepatic fibrogenesis, either directly or through lipid peroxidation (20). Biliary fibrosis is the result of initial hepatocyte injury, with a complex interaction among the inflamatory cells, platelets, Kupffer cells, cytokines and growth factors (21). The cytokines and growth factors are in close relation with oxygen free radicals and inflammation leading to the fibrosis $(17,19)$. In this study, the changes demonstrating bile duct proliferation and fibrosis in expanded portal tracts, including the extension of proliferated bile ducts into lobules, mononuclear cells, and neutrophil infiltration into the widened portal areas, were observed in the BDL group. Our data are corroborated by previous studies reported by other investigators on BDL-induced hepatic fibrosis in animals. In this study, we demonstrated histologically that curcumin significantly reduced fibrosis in BDL rats. Baghdasaryan et al. (22) showed in a recent study that curcumin resulted in an inhibition of cholangiocyte proliferation and a decrease in fibrosis. While Reyes-Gordillo et al. (23) reported that treatment of the BDLgroup rats with curcumin resulted in the disappearance of fibrosis, in our study we demonstrated that curcumin significantly reduced fibrosis.

Bile duct ligation (BDL) induces liver fibrosis having some similarities in etiological and pathological aspects to biliary fibrosis in human beings. The production of lipid peroxides is caused primarily by the damage to the hepatocytes. Lipid peroxides might directly stimulate activated stellate cells for matrix production (24). Although hepatocyte apoptosis characterizes many forms of liver injury, HSCs are responsible for the overabundant and maladaptive generation of matrix proteins in human liver diseases. During liver diseases, HSCs undergo a phenotypic transformation from a quiescent retinoid-storing pericyte to a myofibroblast-like cell secreting matrix proteins (25). The deposition and accumulation of matrix proteins, such as type I collagen, form a thick web of interconnecting fibrous scar referred to as cirrhosis. Although reducing hepatocyte apoptosis attenuates liver injury and inflammation, it is unclear whether inhibiting apoptosis is sufficient to also abrogate stellate cell activation and liver fibrogenesis.

Although the mechanism of liver fibrosis is not fully understood, activated hepatic stellate cells are known to play an important role in connective tissue synthesis and deposition during fibrogenesis (26). Injury of hepatocytes results in the generation of lipid peroxides, which may have a direct stimulatory effect on matrix production by activated stellate cells (3). The activation of hepatic stellate cells involves increased cellular proliferation, increased synthesis of extracellular matrix proteins, and the expression of the activation marker $\alpha$-SMA (27). Previous investigations have demonstrated that BDL causes progressive bile stasis, focal necrosis, bile ductular proliferations, and periportal inflammation in rats (28). Extracellular matrices in liver fibrosis are known to be produced by myofibroblasts that are transformed from fat storing cells. The development of the fibrotic process is thought to be mediated by various fibrogenic mediators (29). In a recent study, Rajagopalan et al. (30) showed that bis-desmethoxycurcumin analog is an effective antifibrotic agent which acts by decreasing both collagen and tissue inhibitors of metalloproteinases. Like Aksu et al.'s (31) studies, we have found in our study that the positive stainings for $\alpha$-SMA were greatly increased, especially in vascular smooth muscle cells and sinusoids and also in the cells of portal ducts, fibrotic septa, perisinuses and around the proliferated bile ducts. The $\alpha$-SMA positive cells in the BDL group were observed to be reduced with the curcumin treatment.

Cholestasis, an impairment in bile formation, occurs in a wide variety of human liver diseases. Hepatocyte apoptosis is currently suspected to be the prominent cell death in cholestasis. In another study, Ogata et al. (32) also examined the effect of fluvastatin treatment on apoptosis after BDL in rats. They reported that BDL markedly increased the percentage 
of TUNEL-positive cells, especially in the ductular proliferation areas, and this increase was significantly suppressed by fluvastatin treatment. Several factors may influence the onset of hepatocyte cell death. Retention and accumulation of toxic hydrophobic bile salts within hepatocyte cause hepatocyte toxicity by inducing apoptosis $(32,33)$. In our study, the number of TUNEL-positive cells in the control group was negligible. When liver sections were TUNEL stained, there was a clear increase in the number of positive cells in the BDL treated rats in the liver parenchyma. Treatment of curcumin markedly reduced the reactivity and the number of TUNEL positive cells.

In this experimental study, we were able to demonstrate the protective effect of curcumin on liver fibrosis in rats given 3 days prior to BDL. In clinical practice it is clear that the treatment will be started after the biliary obstruction and the preobstruction treatment period will lack. To adjust the exact treatment period and time, further experimental and clinical studies are needed.

In conclusion, these findings suggested that curcumin can reduce the hepatic damage in extrahepatic cholestasis by prevention of the oxidative stress, and the inflammatory process. All these findings suggest that curcumin may be a promising new therapeutic agent for cholestatic liver injury.

\section{Conflict of Interest}

No conflict of interest was declared by the authors.

\section{References}

1. Maher JJ, McGuire RF. Extracellular matrix gene expression increases preferentially in rat lipocytes and sinusoidal endothelial cells during hepatic fibrosis in vivo. J Clin Invest 1990; 86:1641-8.

2. Morris JS, Gallo GA, Scheuer PJ, Sherlock S. Percutaneous liver biopsy in patients with large bile duct obstruction. Gastroenterology 1975;68:750-4. [CrossRef]

3. Liu TZ, Lee KT, Chern CL, Cheng JT, Stern A, Tsai LY. Free radical triggered hepatic injury of experimental obstructive jaundice of rats involves overproduction of proinflammatory cytokines and enhanced activation of nuclear factor kappab. Ann Clin Lab Sci 2001;31:383-90

4. Kountouras J, Billing BH, Scheuer PJ. Prolonged bile duct obstruction: a new experimental model for cirrhosis in the rat. $\mathrm{Br} \mathrm{J}$ Exp Pathol 1984;65:305-11.

5. Benedetti A, Alvaro D, Bassotti C, Gigliozzi A, Ferretti G, La Rosa $T$, et al. Cytotoxicity of bile salts against biliary epithelium: a study in isolated bile ductule fragments and isolated perfused rat liver. Hepatology 1997;26:9-21. [CrossRef]

6. Kanter M, Yener Z. A rabbit model for liver fibrosis. Scand J Lab Anim Sci 2001;28:213-23.

7. Strimpakos AS, Sharma RA. Curcumin: preventive and therapeutic properties in laboratory studies and clinical trials. Antioxid Redox Signal 2008;10:511-45. [CrossRef]

8. Punithavathi D, Venkatesan N, Babu M. Curcumin inhibition of bleomycin-induced pulmonary fibrosis in rats. $\mathrm{Br} \mathrm{J}$ Pharmacol 2000;131:169-72. [CrossRef]

9. Kim KM, Pae HO, Zhung M, Ha HY, Ha YA, Chai KY, et al. Involvement of anti-inflammatory heme oxygenase- 1 in the inhibitory effect of curcumin on the expression of proinflammatory inducible nitric oxide synthase in RAW264.7 macrophages. Biomed Pharmacother 2008;62:630-6. [CrossRef]
10. Misko TP, Moore WM, Kasten TP, Nickols GA, Corbett JA, Tilton RG. Selective inhibition of the inducible nitric oxide synthase by aminoguanidine. Eur J Pharmacol 1993;233:119-25. [CrossRef]

11. Jian MY, Koizumi T, Kubo K. Effects of nitric oxide synthase inhibitor on acid aspiration-induced lung injury in rats. Pulm Pharmacol Ther 2005;18:33-9. [CrossRef]

12. Ishak K, Baptista A, Bianchi L, Callea F, De Groote J, Gudat F, et al. Histological grading and staging of chronic hepatitis. J Hepatol 1995;22:696-9. [CrossRef]

13. Hsu SM, Raine $L$, Fanger $H$. Use of avidin biotin-peroxidase complex $(A B C)$ in immunperoxidase techniques: a comparison between $A B C$ and unlabeled antibody (PAP) procedures. J Histochem Cytochem 1981;29:577-80. [CrossRef]

14. Schmitt-Graff A, Kruger S, Bochard F, Gabbiani G, Denk H. Modulation of alpha smooth muscle actin and desmin expression in perisinusoidal cells of normal and diseased human livers. Am J Pathol 1991;138:1233-42.

15. Tracy TF Jr, Fox ES. Molecular and cellular control points in pediatric liver injury and repair. Semin Pediatr Surg 1996;5:175-81.

16. Roggin KK, Kim JC, Kurkchubasche AG, Papa EF, Vezeridis AM, Tracy TF. Macrophage phenotype during cholestatic injury and repair: the persistent inflammatory response. J Pediatr Surg 2001;36:220-8. [CrossRef]

17. Strazzabosco M, Fabris L, Spirli C. Pathophysiology of cholangiopathies. J Clin Gastroenterol 2005;39:90-102. [CrossRef]

18. Marley R, Holt S, Fernando B. Lipoic acid prevents development of the hyperdynamic circulation in anesthetized rats with biliary cirrhosis. Hepatology 1999;29:1358-63. [CrossRef]

19. Karaman A, Iraz M, Kirimlioglu H, Karadag N, Tas E, Fadillioglu E. Hepatic damage in biliary obstructed rats is ameliorated by leflunomide treatment. Pediatr Surg Int 2006;22:701-8. [CrossRef]

20. Parola M, Leonarduzzi G, Robino G, Albano E, Poli G, Dianzani MU. On the role of lipid peroxidation in the pathogenesis of liver damage induced by long-standing cholestasis. Free Radic Biol Med 1996;20:351-9. [CrossRef]

21. Kullak-Ublick GA, Meier PJ. Mechanisms of cholestasis. Clin Liver Dis 2000;4:357-85. [CrossRef]

22. Baghdasaryan A, Claudel T, Kosters A, Gumhold J, Silbert D, Thüringer $\mathrm{A}$, et al. Curcumin improves sclerosing cholangitis in Mdr2-/- mice by inhibition of cholangiocyte inflammatory response and portal myofibroblast proliferation. Gut 2010;59:521-30. [CrossRef]

23. Reyes-Gordillo K, Segovia J, Shibayama M, Tsutsumi V, Vergara $\mathrm{P}$, Moreno MG, et al. Curcumin prevents and reverses cirrhosis induced by bile duct obstruction or $\mathrm{CCl} 4$ in rats: role of TGF-b modulation and oxidative stres. Fundam Clin Pharmacol 2008;22:417-27. [CrossRef]

24. Serviddio G, Pereda J, Pallardo FV, Carretero J, Borras C, Cutrin $\mathrm{J}$, et al. Ursodeoxycholic acid protects against secondary biliary cirrhosis in rats by preventing mitochondrial oxidative stress. Hepatology 2004;39:711-20. [CrossRef]

25. Friedman SL. Molecular regulation of hepatic fibrosis, an integrated cellular response to tissue injury. J Biol Chem 2000;275:2247-50. [CrossRef]

26. Nan JX, Park EJ, Kim HJ, Ko G, Sohn DH. Antifibrotic effects of the methanol extract of Polygonum aviculare in fibritic rats induced by bile duct ligation and scission. Biol Pharm Bull 2000;23:240-3. [CrossRef]

27. Miyazaki H, Van Eyken P, Roskams T, De Vos R, Desmet VJ. Transient expression of tenascin in experimentally induced cholestatic fibrosis in rat liver: an immunohistochemical study. J Hepatol 1993;19:353-66. [CrossRef]

28. Bolt MJ, Sitrin MD, Favus MJ, Rosenberg IH. Hepatic vitamin D 25- hydroxylase: inhibition by bile duct ligation or bile salts. Hepatology 1981;1:436-40. [CrossRef]

29. Akiyoshi H, Terada T. Mast cell, myofibroblast and nerve terminal complexes in carbon tetrachloride-induced cirrhotic rat livers. J Hepatol 1998;29:112-9. [CrossRef] 
30. Rajagopalan R, Sridharana S, Menon VP. Hepatoprotective role of bis-demethoxy curcumin analog on the expression of matrix metalloproteinase induced by alcohol and polyunsaturated fatty acid in rats. Toxicol Mech Methods 2010;20:252-9. [CrossRef]

31. Aksu B, Umit H, Kanter M, Guzel A, Aktas C, Civelek S, et al. Effects of methylene blue in reducing cholestatic oxidative stress and hepatic damage after bile-duct ligation in rats. Acta Histochem 2010;112:259-69. [CrossRef]
32. Ogata Y, Takahashi M, Takeuchi K, Ueno S, Mano H, Ookawara S, et al. Fluvastatin induces apoptosis in rat neonatal cardiac myocytes: a possible mechanism of statin-attenuated cardiac hypertrophy. J Cardiovasc Pharmacol 2002;40:907-15. [CrossRef]

33. Soma MR, Gabbiani G, Fumagalli R, et al. Relationship between mevalonate pathway and arterial myocyte proliferation: in vitro studies with inhibitors of HMG-CoA reductase. Atherosclerosis 1993;101:117-25. [CrossRef] 